\title{
Rights and responsibilities of users of electronic health records
}

\author{
Dean F. Sittig PhD, Hardeep Singh MD MPH
}

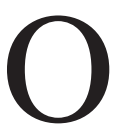

ver the last 10 years the governments of Australia, ${ }^{1}$ Belgium, ${ }^{2}$ Canada, ${ }^{3}$ Denmark ${ }^{4}$ the United Kingdom ${ }^{5}$ and most recently the United States, ${ }^{6}$ have all made longterm, multibillion dollar investments in health information technologies, including electronic health records. Although the definition of electronic health records might vary across countries, most systems are widely accessible across a health care network and provide a computerbased user interface that replaces the paper chart. The primary goal of these initiatives in health information technologies is to transform the collection, display, transmission and storage of patient data with the aim of improving health. A secondary goal is to use patient data to improve the system of health care delivery. The rationale for these investments stems from numerous concerns of quality and safety related to paper-based systems, which include problems with legibility, access limited to a single provider at a single location, difficulties with aggregating information from multiple records, and problems maintaining confidentiality of records and accurate backup copies. ${ }^{7}$ Comprehensive, well-implemented electronic health records with advanced clinical decision support interventions have potential to reduce errors with medications ${ }^{8}$ and to increase the quality, efficiency and reliability of information transfer., ${ }^{910}$

Despite progress in the use of electronic health records, ${ }^{11}$ their adoption has resulted in larger than expected challenges in day-to-day clinical processes..$^{12}$ For example, processing electronic information can reduce the productivity of clinicians and increase their workloads, ${ }^{13-15}$ and other disruptions of workflow can result in safety concerns owing to loss of attention and situational awareness. ${ }^{16}$ Thus, clinicians may perceive that the costs of electronic health records (e.g., in time or money, or from required changes in workflow) outweigh direct benefits to themselves, whereas patients and payers appear to benefit more readily. ${ }^{17}$ Clinicians require assurances that electronic health records will deliver the features and functions they need and that the regulatory environment will support them.
Based on recent literature and our research in informatics and health care quality and safety, we identified 10 emerging topics that, if addressed, could overcome some of these challenges. Topics were based on our recently developed eightdimension sociotechnical model of safe and effective use of electronic health records..$^{18}$ These topics were circulated among several colleagues, including practising clinicians, informaticists and computer scientists, who offered their feedback. This was followed by presentations at four international scientific meetings with multidisciplinary audiences who gave additional feedback. We used this input to refine the topics and generate 10 "rights" and responsibilities of clinicians with a goal of making them as universally acceptable and applicable as possible.

\section{Contextualizing topics as rights and responsibilities of clinicians}

Some disruption of workflow is inevitable with the implementation of electronic health records, which requires modification of long-standing work processes derived from paper-based systems. In addition, clinicians' use of electronic health records often results in loss of autonomy because of increased external oversight (i.e., clinician profiling) and control (i.e., orderable medications limited to formulary) facilitated by the features and functions of electronic systems. Concomitantly, practising clinicians are often at a relative disadvantage when negotiating issues related to electronic health records with other

\section{KEY POINTS}

- Despite the potential benefits of electronic health records, clinicians have experienced several challenges in their adoption and use.

- To encourage debate on strategies to overcome these challenges, we developed a set of 10 "rights" of clinicians that represent important features, functions and user privileges of electronic health records that clinicians need to provide safe, high-quality care.

- Each right is accompanied by a corresponding responsibility of clinicians, without which the ultimate goal of improving quality of health care might not be achieved. 
stakeholders (e.g., health care administrators, vendors of health information technologies, governments, insurance companies or other payers, and policy-makers). To preserve a balance and to encourage debate between clinicians and other stakeholders involved, we discuss these topics in the context of what front-line practising clinicians would want as professional rights (i.e., not merely desirable but must-have electronic health record features, functions and user privileges that are important to provide the highest quality, safest and most cost-effective care). Each right is accompanied by a corresponding responsibility of clinicians, without which the ultimate goal of improving the quality of health care might not be achieved. ${ }^{19}$

We acknowledge that contextualizing these topics as rights of clinicians has important implications for other stakeholders, but these issues must be addressed to move forward in the adoption of electronic health records. Although these rights are clearly not of the same magnitude or universal importance as the World Health Organization's human rights-based approach to health ${ }^{20}$ or the Hippocratic Oath, ${ }^{21}$ recognition of these rights could reduce unintended adverse consequences on patient care and clinicians' livelihoods. These rights could be a foundation upon which designers, developers, implementers, policy-makers and, most importantly, users of health information technologies can co-create a new age of computer-assisted health care. ${ }^{22}$

\section{Ten rights and responsibilities}

\section{Uninterrupted access to records}

Extended outages of electronic health records pose a substantial risk to patient care. Therefore, clinicians have the right to have a system they can continuously access via a secure, organizationally approved, network-attached device. Although no device or system can be $100 \%$ reliable, vendors of electronic health records, institutions and physicians must work together to design, develop, implement and use fail-safe equipment and processes for downtime to ensure that patient care continues in the event of an outage.

Clinicians have the responsibility to protect their passwords, log off the system when done, and access only records of patients under their care or within their administrative purview.

\section{No missing data}

Clinicians have the right to see all clinical data that were captured in the normal course of care for each of their patients. ${ }^{23}$ Amid concerns about patient privacy, some argue that patients or clinicians should be able to "hide" specific data (e.g., records of psychiatric or substance-abuse treatment $)^{24}$ or even to "opt out" of having their data available to other clinicians. ${ }^{25,26}$ This withheld data unnecessarily increases the liability of clinicians.

Clinicians have the responsibility to ensure that the availability of all patient data on their desktops does not replace the time-honoured tradition of observing, listening to and examining patients. ${ }^{27}$

\section{Succinct patient summaries}

Current electronic health records contain a wealth of clinical data. As more communitywide health information systems come online, the amount of data available for review will grow exponentially, increasing the likelihood that relevant information will be overlooked. Clinicians thus have the right to electronic health records that provide succinct summaries of their patients' medical problems, medications, laboratory results, vital signs and progress notes. ${ }^{23}$ Some systems currently have "summary" views that arrange data by type (e.g., all laboratory results together) and time (e.g., most recent data first) on different screens. However, future innovations in this area are needed. For example, problem-oriented summaries that integrate data from different sources on one screen could potentially facilitate better information processing and exert a lower cognitive load.

Clinicians conversely have the responsibility to maintain accurate, up-to-date problem lists using a controlled clinical terminology (e.g., SNOMED CT [Systematized Nomenclature of Medicine - Clinical Terms]) and link them with corresponding diagnostic and treatment elements through the electronic system to prevent "incomplete care." ${ }^{.28}$

\section{Ability to override computer-generated interventions}

Clinicians receive a large number of computergenerated alerts, many of which are considered unnecessary. ${ }^{29}$ These alerts can cause cognitive overload and fatigue. Even more troublesome, some alerts cannot be overridden because of institutional configuration decisions requiring "hard stops" (i.e., the computer prohibits completion of the task). ${ }^{30}$ Clinicians should have the right to override, but not permanently disable, any computer-generated clinical intervention. In the event of an exceptionally hazardous scenario or when the organization's clinical leadership decides that a particular order should never occur, clinicians should be required to obtain a co-signature from a higher-ranking or more experienced clinician before completing the task of overriding an alert. Disallowing overrides 
through hard stops implies that computers have access to more accurate data and greater medical knowledge and expertise than clinicians. In reality, computers are often not able to interpret or convey the clinical context for many reasons: unavailable or inaccurate data, errors in logical processing (e.g., software bugs) and situationspecific clinical exceptions (e.g., user request for blood transfusion denied by a computer-generated intervention that did not capture active bleeding since last hemoglobin result).

Clinicians have the responsibility to justify overrides and be accountable for decisions by agreeing to have their actions reviewed. Additionally, they must participate on clinical decision support oversight committees and work with other stakeholders to review, redesign, test, re-implement or remove clinical decision support interventions that are judged ineffective. ${ }^{31}$

\section{Rationale for clinical decision support}

Advanced clinical decision support interventions are necessary if electronic health records are to generate expected improvements in the quality, safety and effectiveness of health care. Nevertheless, clinicians have the right to request and receive a clear, evidence-based rationale at the point of care for all computer-generated interventions (e.g., alerts or reminders).

Physicians have the responsibility to carefully consider computer-generated interventions. Blindly following or ignoring clinical decision support interventions can lead to errors. ${ }^{32}$

\section{Reliable performance measurement}

Performance measurement based on electronic health records is inevitable. Current methods of data collection and measurement are not failsafe and often measure what is easy to measure. ${ }^{33}$ To correct discrepancies, clinicians have the right to review all processes based on electronic health records used to generate reports that inform policy decisions or performance measurement. ${ }^{34}$ All computer-based measurements should have unambiguous exclusion criteria and allow clinicians to identify patients to whom the measure does not apply (e.g., no diabetic foot examinations on patients with bilateral below-the-knee amputations). If needed, clinicians should have access to queries, data extracts and statistical methods used. Proactive collaboration with stakeholders such as organizational leaders will help ensure that performance measurements are valid.

To ensure continuous quality improvement, physicians have the responsibility to review the performance feedback they are provided and act on it.

\section{Safe electronic health records}

Software errors and usability issues in electronic health records are increasingly linked to safety hazards that can lead to patient harm ("e-iatrogenesis"). ${ }^{35,36}$ Clinicians have the right to expect that all errors related to electronic health records will be reported, investigated and resolved in a timely manner. ${ }^{37}$ Vendors and health care organizations responsible for maintaining the electronic health records should make these reports, along with their responses, publicly available so that others can learn from them. ${ }^{38}$

Clinicians have the responsibility to report, help investigate and learn from safety hazards related to electronic health records.

\section{Training and assistance}

State-of-the-art electronic health records are complex tools designed to facilitate the entry, storage, review, interpretation and transmission of patient data. Clinicians have the right to receive training - either from their vendor or their health care organization - in all features of electronic health records. Ongoing training and support should include access to online instruction and availability of real-time assistance while caring for patients, preferably in person. ${ }^{39}$

Clinicians have the responsibility to maintain a high level of user proficiency with the same level of diligence as for other clinical skills. To improve efficiency and safety, clinicians must learn to type, complete training in electronic health records and show competence in use of all functions required to care for patients (e.g., enter orders, add problems and initiate referrals). Finally, clinicians are responsible for asking for help when they reach limits of their proficiency.

\section{Compatibility with real-world clinical workflows}

Clinicians have the right to safe, effective and usable electronic health records that contain evidence-based, problem- and task-specific order sets, documentation templates and information displays designed to be compatible with their clinical workflows. ${ }^{40}$

Clinicians have the responsibility to work with vendors and local information technologists to design, develop and implement data entry, data review and clinical decision support tools, and to modify previous paper-based workflows to overcome limitations of electronic health records.

\section{Facilitation of communication, coordination and teamwork}

Electronic health records fundamentally change the way clinicians coordinate their work activities, communicate and collaborate to deliver 
high-quality, safe and effective health care. ${ }^{41}$ Most current electronic health records are not optimal for team-based care that includes patients and their caregivers. ${ }^{42}$ Clinicians have the right to future innovations in electronic health records that facilitate complex communication and coordination tasks across time, space and people.

Clinicians have the responsibility to use electronic health records in ways that foster teamwork. They must document their findings, decisions and actions succinctly, avoid reckless copy and paste, and respond to human- and computergenerated requests for information and action in a timely manner.

\section{Next steps}

Although our article lays the groundwork for future debate, it has several limitations. First, we do not specifically outline who might enforce these clinician rights and responsibilities or what alternatives could be pursued if these conditions are not met. However, we believe it is premature for us to do so at this stage of conceptualization without further debate and agreement. Second, we recognize that even with consensus regarding the necessity of these rights, delivering them in the short term will be difficult using today's technology and in today's sociopolitical and economic environments. Our goal, however, is to lay the foundation for a long-term agenda for providing clinicians access to safe, effective and easy-to-use electronic health records that support their cognitive and physical work processes. Finally, we recognize that achieving high-quality and affordable health care is a complex, sociotechnical endeavour. Thus, these clinician rights might not be the perfect solution because there are many competing and often opposing views of the best way to accomplish this endeavour.

A competing view is that other stakeholders in this debate, including payers, administrators, policy-makers and patients, are also entitled to an equally important and valid set of rights, which may conflict with one or more of the clinicians' rights. Payers, administrators and policy-makers, for example, have the right to mandate use of functions related to electronic health records that promote patient safety (e.g., order entry), prohibit use of functions that jeopardize patient safety (e.g., use of a nonsecure, Web-based calendar to facilitate clinician workflow $^{43}$ or use of text messaging for order entry ${ }^{44}$ ), enforce specific rules and regulations (e.g., reprimanding users for unauthorized access to patient data), create new clinical decision sup- port interventions to encourage efficient, effective, evidence-based care, and evaluate clinicians' performance using data from electronic health records. Likewise, patients have the right to access their data, have any errors of data entry corrected, obtain a list of everyone who has viewed their data, confidentially communicate electronically with their providers, and request that certain data not be used for purposes other than research or public health benefit without their written consent (e.g., no selling of data). ${ }^{45}$

In the event that one group's rights infringe upon those of another group, we are optimistic that organizations and the constituents they represent will participate in an open, constructive debate on these rights and reach consensus. ${ }^{46}$ If this consensus were formalized and ratified, then relevant stakeholders (e.g., vendors, implementers, professional boards, hospital committees, users, patients and government agencies) could work together to design and implement electronic health records and the corresponding policies, procedures and regulations required to ensure these rights.

\section{Summary}

The 10 key issues discussed here form a set of features, functions and user privileges of electronic health records that clinician users require to deliver high-quality, safe and effective care. Issues discussed are generalizable to clinicians and electronic health records across the globe. Addressing these rights and responsibilities comprehensively will be challenging but can make the care delivered through the electronic health records-based work system safer and more efficient.

\section{References}

1. HealthConnect Implementation Strategy. Version 2.1. Canberra (Australia): Commonwealth of Australia; 2005. Available: www .health.gov.au/internet/hconnect/publishing.nsf/Content/archive -docs/\$File/implementation.pdf (accessed 2012 Jan. 25).

2. France FR. eHealth in Belgium, a new "secure" federal network: role of patients, health professions and social security services. Int J Med Inform 2011;80:e12-6.

3. Blueprint EHRS: an interoperable EHR framework. Version 2. Canada Health Infoway; 2006. Available: https://knowledge .infoway-inforoute.ca/EHRSRA/doc/EHRS-Blueprint.pdf (accessed 2012 Jan. 25).

4. Protti D, Johansen I. Widespread adoption of information technology in primary care physician offices in Denmark: a case study. Issue Brief (Commonw Fund) 2010;80:1-14.

5. House of Commons Public Accounts Committee. The National Programme for IT in the NHS: progress since 2006. Second report of session 2008-09. London (UK): The Stationery Office; 2009. Available: www.publications.parliament.uk/pa/cm200809 /cmselect/cmpubacc/153/153.pdf (accessed 2012 Jan. 25).

6. Blumenthal D. Wiring the health system - origins and provisions of a new federal program. N Engl J Med 2011;365:2323-9.

7. Powsner SM, Wyatt JC, Wright P. Opportunities for and challenges of computerisation. Lancet 1998;352:1617-22.

8. Bates DW, Leape LL, Cullen DJ, et al. Effect of computerized physician order entry and a team intervention on prevention of 
serious medication errors. JAMA 1998;280:1311-6.

9. Singh H, Arora HS, Vij MS, et al. Communication outcomes of critical imaging results in a computerized notification system. J Am Med Inform Assoc 2007;14:459-66.

10. Singh H, Naik AD, Rao R, et al. Reducing diagnostic errors through effective communication: harnessing the power of information technology. J Gen Intern Med 2008;23:489-94.

11. Protti D. Comparison of information technology in general practice in 10 countries. Healthc Q 2007;10:107-16.

12. Westbrook JI, Braithwaite J. Will information and communication technology disrupt the health system and deliver on its promise? Med J Aust 2010;193:399-400.

13. Poissant L, Pereira J, Tamblyn R, et al. The impact of electronic health records on time efficiency of physicians and nurses: a systematic review. J Am Med Inform Assoc 2005;12:505-16.

14. Magrabi F, Ong MS, Runciman W, et al. An analysis of computer-related patient safety incidents to inform the development of a classification. J Am Med Inform Assoc 2010;17:663-70.

15. Committee on Patient Safety and Health information Technology Board on Healthcare Services. Health IT and patient safety: building safer systems for better care. Washington (DC): The National Academies Press; 2011.

16. Singh H, Giardina TD, Petersen LA, et al. Exploring situational awareness in diagnostic errors in primary care. BMJ Qual Saf 2012;21:30-8

17. Sprivulis P, Walker J, Johnston D, et al. The economic benefits of health information exchange interoperability for Australia. Aust Health Rev 2007;31:531-9.

18. Sittig DF, Singh H. A new sociotechnical model for studying health information technology in complex adaptive healthcare systems. Qual Saf Health Care 2010;19(Suppl 3):i68-74.

19. Good medical practice: the duties of a doctor registered with the General Medical Council. Med Educ 2001;35(Suppl 1):70-8

20. World Health Organization. A human rights-based approach to health. Available: www.who.int/hhr/news/hrba_info_sheet.pdf (accessed 2011 Nov. 27)

21. The Hippocratic Oath [Translated by Michael North]. Bethesda (MD): US National Library of Medicine; 2002. Available: www .nlm.nih.gov/hmd/greek/greek_oath.html (accessed 2011 Apr. 7).

22. Stead WW, Searle JR, Fessler HE, et al. Biomedical informatics: changing what physicians need to know and how they learn. Acad Med 2011:86:429-34

23. Committee opinion no. 472: Patient safety and the electronic health record. Obstet Gynecol 2010;116:1245-7.

24. Popovits RM. Confidentiality law: Time for change? Behav Healthc 2010;30:11-3.

25. Watson N. Patients should have to opt out of national electronic care records: FOR. BMJ 2006;333:39-40.

26. Halamka JD. Patients should have to opt out of national electronic care records: AGAINST. BMJ 2006;333:41-2.

27. Verghese A. Culture shock - patient as icon, icon as patient. N Engl J Med 2008;359:2748-51.

28. Gandhi TK, Zuccotti G, Lee TH. Incomplete care - on the trail of flaws in the system. N Engl J Med 2011;365:486-8.

29. Isaac T, Weissman JS, Davis RB, et al. Overrides of medication alerts in ambulatory care. Arch Intern Med 2009;169:305-11.

30. Strom BL, Schinnar R, Aberra F, et al. Unintended effects of a computerized physician order entry nearly hard-stop alert to prevent a drug interaction: a randomized controlled trial. Arch Intern Med 2010;170:1578-83.

31. Wright A, Sittig DF, Ash JS, et al. Governance for clinical decision support: case studies and recommended practices from leading institutions. J Am Med Inform Assoc 2011;18:187-94.

32. McCoy AB, Waitman LR, Lewis JB, et al. A framework for evaluating the clinical impact of computerized medication safety alerts. J Am Med Inform Assoc 2011; Aug. 17 [Epub ahead of pint].

33. Ofri D. Quality measures and the individual physician. $N$ Engl J Med 2010;363:606-7.

34. Department of Health and Human Services Centers for Medicare \& Medicaid Services. 42 CFR Part 401, CMS-5059-F, RIN 0938-AQ17. Availability of Medicare data for performance measurement. Available: www.gpo.gov/fdsys/pkg/FR-2011-12-07 $/ \mathrm{html} / 2011-31232 . \mathrm{htm}$ (accessed 2012 Jan. 25).

35. Myers RB, Jones SL, Sittig DF. Review of reported clinical information system adverse events in US Food and Drug Administration databases. Appl Clin Inform 2011;2:63-74.

36. Institute of Medicine. Health IT and patient safety: building safer systems for better care. Washington (DC): The National Academies Press; 2012. Available: http://iom.edu/Reports /2011/Health-IT-and-Patient-Safety-Building-Safer-Systems-for -Better-Care.aspx (accessed 2011 Dec. 16).
37. Singh H, Classen DC, Sittig DF. Creating an oversight infrastructure for electronic health record-related patient safety hazards. J Patient Saf 2011;7:169-74.

38. Walker JM, Carayon P, Leveson N, et al. EHR safety: the way forward to safe and effective systems. J Am Med Inform Assoc 2008:15:272-7.

39. Ash JS, Stavri PZ, Dykstra R, et al. Implementing computerized physician order entry: the importance of special people. Int J Med Inform 2003;69:235-50.

40. Karsh B-T. Clinical practice improvement and redesign: how change in workflow can be supported by clinical decision support. Rockville (MD): Agency for Healthcare Research and Quality; 2009.

41. Campbell EM, Guappone KP, Sittig DF, et al. Computerized provider order entry adoption: implications for clinical workflow. J Gen Intern Med 2009;24:21-6.

42. Thomas EJ. Improving teamwork in healthcare: current approaches and the path forward. BMJ Qual Saf 2011;20:647-50.

43. Monthly report to congress on data incidents. Nov 1-28, 2010. Washington (DC): United States Department of Veterans Affairs; 2010. Available: www.va.gov/ABOUT_VA/docs/monthly_rfc nov2010.pdf (accessed 2011 Nov. 27)

44. The Joint Commission. Texting orders. Oakbrook Terrace (IL): The Commission; 2011. Available: www.jointcommission.org /standards_information/jcfaqdetails.aspx?StandardsFaqId=401 \&ProgramId $=1$ (accessed 2011 Nov. 27).

45. Smith M. Patient's Bill of Rights - a comparative overview (PRB 01-31E). Ottawa (ON): Library of Parliament; 2002. Available: http://dsp-psd.pwgsc.gc.ca/Collection-R/LoPBdP /BP/prb0131-e.htm (accessed 2011 Nov. 26).

46. Beard L, Schein R, Morra D, et al. The challenges in making electronic health records accessible to patients. J Am Med Inform Assoc 2012;19:116-120.

Competing interests: Dean Sittig's institution received a Strategic Health IT Advanced Research Projects (SHARP) contract from the Office of the National Coordinator for Health Information Technology (ONC no. 10510592) and the National Library of Medicine (R01-LM006942). Hardeep Singh's institution received funds from the Mentored Patient-Oriented Research Career Development Award (K23) program from the National Institutes of Health (grant no. K23CA125585), the VA National Center for Patient Safety, the Agency for Healthcare Research and Quality (R18 HS 017820) and a SHARP contract from the Office of the National Coordinator for Health Information Technology (ONC no. 10510592). Dr. Singh is also supported by the Houston VA Health Services Research and Development Center of Excellence (HFP90-020). These funding sources had no role in the preparation, review or approval of the manuscript. The views expressed in this article are those of the authors and do not represent the views of the Department of Veterans Affairs or other funders.

Affiliations: From the Memorial Hermann Center for Healthcare Quality and Safety, and the National Center for Cognitive Informatics and Decision Making, School of Biomedical Informatics, University of Texas Health Sciences Center (Sittig), Houston, Tex.; the Houston VA Health Services Research and Development Center of Excellence, and the Center of Inquiry to Improve Outpatient Safety Through Effective Electronic Communication, Michael E. DeBakey Veterans Affairs Medical Center, and the Section of Health Services Research, Department of Medicine, Baylor College of Medicine (Singh), Houston, Tex.

Contributors: Both authors drafted the article, revised it critically for important intellectual content and approved the final version submitted for publication.

Acknowledgements: The authors thank Dr. Ben Shneiderman for encouraging us to explore this topic. The authors also thank Drs. Elmer V. Bernstam, Annie Bradford, Gilad J. Kuperman, Daniel G. Miller, Laura A. Petersen, Ryan P. Radecki, Heidi V. Russell, M. Michael Shabot, Ben Shneiderman, Geeta R. Singhal and Eric J. Thomas for their helpful comments on early drafts of this manuscript. 